\title{
(2) OPEN ACCESS \\ Thyroid storm in the second stage of labour: a case report
}

\author{
Yudianto Budi Saroyo, Achmad Kemal Harzif @ • Beryliana Maya Anisa, \\ Fistyanisa Elya Charilda
}

Department of Obstetrics and Gynecology, Faculty of Medicine, Universitas Indonesia; Dr. Cipto Mangunkusumo General Hospital, Jakarta Pusat, Indonesia

Correspondence to Dr Achmad Kemal Harzif; kemal.achmad@gmail.com

Accepted 14 June 2021

Check for updates

(c) BMJ Publishing Group Limited 2021. Re-use permitted under CC BY-NC. No commercial re-use. See rights and permissions. Published by BMJ.

To cite: Saroyo YB, Harzif AK, Anisa BM, et al. BMJ Case Rep 2021;14:e243159. doi:10.1136/bcr-2021243159

\section{SUMMARY}

A thyroid storm (or thyroid crisis) is an emergency in endocrinology. It is a form of complication of hyperthyroidism that can be life-threatening. Inadequate control of hyperthyroidism in pregnancy could develop into thyroid storm, especially in the peripartum period. We present a woman came in the second stage of labour, with thyroid storm, superimposed pre-eclampsia, acute lung oedema and impending respiratory failure. Treatment for thyroid storm, preeclampsia protocol and corticosteroid was delivered. The baby was born uneventfully, while the mother was discharged after 5 days of hospitalisation. Delivery is an important precipitant in the development of thyroid storm in uncontrolled hyperthyroidism in pregnancy. Although very rare, it can cause severe consequences. Diagnosis and treatment guidelines for thyroid storm were available and should be done aggressively and immediately. Uncontrolled hyperthyroidism should be prevented by adequate control in thyroid hormone levels, especially before the peripartum period.

\section{BACKGROUND}

Hyperthyroidism in pregnancy is rare, occurring in only 1-4 in 1000 pregnancies. The incidence of hyperthyroidism in pregnancy is about $0.2 \%$ and most cases are subclinical. ${ }^{1}$ Thyroid storm is a rare complication of improper treatment of hyperthyroidism in pregnancy. ${ }^{2}$ A thyroid storm is precipitated when hyperthyroidism effects surpass the patient's ability to compensate cardiovascular, thermoregulatory and metabolic systems. ${ }^{3}$ The risk of developing thyroid storm in pregnant hyperthyroid patients can be 10 times higher than in the general population. ${ }^{4}$ Precipitant of thyroid storm includes thyroid surgery, withdrawal of antithyroid drugs, infection, emotional stress and trauma. ${ }^{3}$ Several obstetric conditions that can precipitate thyroid storm include pre-eclampsia, induction of labour, surgery and pregnancy itself. ${ }^{4}$

\section{CASE PRESENTATION}

A 20-year-old woman was admitted to the emergency room due to the second stage of labour on gravida two parity one 29 weeks of gestational age, singleton lives intrauterine, mother with superimposed pre-eclampsia with severe features and history of uncontrolled thyroid disease. Patient was diagnosed as hyperthyroidism since 5 years before admission, but never took adequate treatment. She had bad antenatal care and did only once visit to the midwife without any written data, but she was told that her blood pressure was high and given nifedipine $10 \mathrm{mg}$ once per day without her taking the medicine. During this pregnancy, she had no history of screening for hyperthyroidism, neither does she took any medicine to lower her thyroid levels. The patient came to emergency room by herself due to regular contraction 6 hours before admission. The patient was in agitation state of consciousness, she had Glasgow Coma Score of 12 consisted of 3 for eye opening response score, 4 for verbal response score and 5 for motoric response score. Her blood pressure in the emergency room was $220 / 120 \mathrm{~mm}$ $\mathrm{Hg}$, and her heart rate 156 times/min. She had fever with temperature of $38.4^{\circ} \mathrm{C}$ and an increased respiratory rate of 40 times/min with oxygen saturation $95 \%$ in room air.

\section{INVESTIGATIONS}

In the general examination, the patient had bilateral protruding eyes suggesting exophthalmos. Diffuse struma in the neck was palpable, with no bruit. Auscultation in both lungs grade $3 / 6$ loudest on the apex with rales in the bilateral bottom side of the lungs. Extremities were warm, there was bilateral pitting oedema. In the obstetric examination, fundal height was $30 \mathrm{~cm}$, with regular contractions of four times in $10 \mathrm{~min}$ with a duration of $45 \mathrm{~s}$. Fetal heart rate was 140 beats/min. Vaginal touche examination revealed a fully dilated cervix, no amniotic membrane was present and fetal feet were palpable on station +2 . Patient was underwent laboratory examination, such as blood gas analysis, urinalysis, ureum creatinine level, aspartate aminotransferase (AST)/alanine aminotransferase (ALT) level and antigen swab of SARS-CoV-2 as the COVID-19 screening protocol in our hospital. Her blood gas analysis showed a little bit increasing of $\mathrm{pH}$ (7.455) while the $\mathrm{HCO}_{3}$ decreased to $17.8 \mathrm{mmol} / \mathrm{L}$ and her $\mathrm{pCO}_{2}$ decreased to $25.1 \mathrm{mmol} / \mathrm{L}$, in urinalysis examination there was proteinuria +2 and haematuria +1 . In addition, her electrogram showed sinus tachycardia. Her thyroid stimulating hormone (TSH) and FT4 level come afterwards, and showed low TSH $(<0.02 \mu \mathrm{IU} / \mathrm{mL})$ and high free T4 $(3.75 \mathrm{ng} / \mathrm{dL})$, her lactate dehydrogenase $(\mathrm{LDH})$ was $547 \mathrm{U} / \mathrm{L}$ as well.

After quick examination, we concluded this patient had second stage of labour on gravida two parity one 29 weeks of gestational age, singleton lives intrauterine, mother with thyroid storm, superimposed pre-eclampsia with severe features, acute lung oedema and impending respiratory failure. 


\section{DIFFERENTIAL DIAGNOSIS}

Based on the hypertension condition with mean arterial pressure more than $120 \mathrm{~mm} \mathrm{Hg}$ and we found proteinuria followed by increasing LDH level, we first suggested this patient got pre-eclampsia condition compounded by HELLP (hemolysis, elevated liver enzyme and low platelet) syndrome. Nevertheless, there was no increasing of AST/ALT level in this patient and her platelet count still in normal limit, the diagnosis can be eliminated. We also found her blood glucose increased to $143 \mathrm{mg} / \mathrm{dL}$ but we thought it as reactive hyperglicemia condition because the blood glucose level was decreasing after we did re-evaluation.

Moreover, the patient came to the hospital with dyspnoea, with her respiratory rate 40 times/min and her oxygen saturation $95 \%$ in room air. In this pandemic condition, initially we suspect SARS-CoV-2 infection. However, without any previous coughing, fever symptom, her antigen swab of SARS-CoV-2 IgG/ IgM showed non-reactive result and her chest X-ray represented cardiomegaly with lung oedema appearance compounded by suspected bilateral pleural effusion, we temporarily set aside this differential diagnosis until the PCR swab result come out.

\section{TREATMENT}

The patient was given a non-rebreathing mask with oxygen $15 \mathrm{~L} /$ min, hereinafter her oxygen saturation level was going up. Preeclampsia protocol was carried out immediately. We gave bolus magnesium sulphate $\left(\mathrm{MgSO}_{4}\right)$ 40\% $4 \mathrm{~g}$ continued by $1 \mathrm{~g}$ per hour as anticonvulsant agent and neuroprotector for the baby. We added nifedipine $10 \mathrm{mg}$ every $20 \mathrm{~min}$ four times to lower her blood pressure. For her thyroid condition we delivered propranolol $40 \mathrm{mg}$, propylthiouracil (PTU) $600 \mathrm{~mL}$, and 5 drops of Lugol iodine 2\%. Furthermore, as this patient came with bad antenatal care and we were not sure about her gestational age, also to prevent respiratory distress and interventricular haemorrhage we gave dexamethasone $12 \mathrm{mg}$ single shot. Fetal foot extraction along with episiotomy was performed afterwards, and delivery was successful $5 \mathrm{~min}$ after this patient came to the emergency room. A baby girl was born, with a birth weight of $1950 \mathrm{~g}$, length of $38 \mathrm{~cm}$ and a $5 \mathrm{~min}$ apgar score of $7 / 8$. Amniotic fluid was scanty and the placenta was delivered completely after $15 \mathrm{~min}$. Episiotomy wound was closed by perineorrhaphy. In the third phase of labour her blood pressure slowly decreased to $180 / 100 \mathrm{~mm} \mathrm{Hg}$, her pulse was still in 140 times/min, saturation oxygen was $96 \%$ using non-rebreathing mask oxygen $15 \mathrm{~L} / \mathrm{min}$, her respiration rate came to 30 times/min but her temperature were not going down.

In the fourth phase of labour, the patient's blood pressure slowly decreases to $134 / 88 \mathrm{~mm} \mathrm{Hg}$ and her pulse slowed down to 120 times/min, her temperature normalised to $37^{\circ} \mathrm{C}$ and she was getting alert with consciousness level became compos mentis.

The baby was born with APGAR to score 7/8. Then, she got CPAP (continous positive airway pressure) with $\mathrm{FiO}_{2} 21 \%$ and PEEP (positive end expiratory pressure) 7 to help her breathing.

\section{OUTCOME AND FOLLOW-UP}

Collaborative management was done by endocrinologists from internal medicine and obstetricians, and the patient was discharged after 5 days of treatment. The paediatric checked for the baby's free T4 and the result was within normal limit $(1.87 \mathrm{ng} / \mathrm{dL})$. The baby's Ballard score similar with 35 weeks of gestation age which showed a discrepancy between prior gestational age that can be caused by her irregular menstruation cycle and no antenatal care data available. The mother's TSH and free
T4 level come afterwards, and showed low TSH $(<0.02 \mu \mathrm{IU} /$ $\mathrm{mL})$ and high free T4 $(3.75 \mathrm{ng} / \mathrm{dL})$ which similar with hyperthyroid condition. Patient was discharged and the follow-up was continued in outpatient clinic.

\section{DISCUSSION}

Our patient was admitted to the emergency room due to second stage of labour on gravida two parity one 29 weeks of gestational age, singleton lives intrauterine; mother with thyroid storm, superimposed pre-eclampsia with severe features, acute lung oedema and impending respiratory failure. Previously, this patient had inadequate hyperthyroid treatment. She has been diagnosed with hyperthyroidism since she was 15 years old, but the patient only admitted to buying over-the-counter drugs without a prescription and took them only in the presence of symptoms. Our patient also had bad antenatal care. She came to the midwife once and lost her antenatal care data, but she was told that her blood pressure is high and she was given nifedipine $10 \mathrm{mg}$ once per day without her taking the medicine. During this pregnancy, she had no history of screening for her hyperthyroidism, neither does she took any medicine to lower her thyroid levels.

Thyroid storm is most diagnosed clinically. Laboratory findings are of little importance since they cannot distinguish uncomplicated thyrotoxicosis with impending thyroid storm, and could not provide a diagnosis. Thyroid storm is diagnosed in patients with a Burch-Wartofsky Point Scale (BWPS) of $\geq 45$ or Japanese Thyroid Association categories of thyroid storm 1 or $2 .^{5}$ The BWPS took into accord the patient's thermoregulatory dysfunction, central nervous system effects, gastrointestinalhepatic dysfunction, cardiovascular dysfunction and precipitant history. ${ }^{3}$ Patients meeting these criteria with a systemic decompensation need to be managed aggressively. In patients with impending thyroid storm (BWPS of 25-44), aggressive therapy could be done based on clinical judgement. ${ }^{5}$ In this case, the patient's Burch and Wartofsky criteria score is 50, highly suggestive of thyroid storm, needing immediate aggressive treatment. We use Modified Early Warning Score (MEOWS) for assessing the severity of this case. MEOWS is early detection of clinical signs of deterioration in women who were developing critical illnesses. Her MEOWS was 29 and categorised as red criteria.

We gave emergency treatment for our patients consecutively based on the airway, breathing and circulation. We ensured her airway is clear before giving further treatment. As this patient had hypertension with blood pressure up to $220 / 120 \mathrm{~mm} \mathrm{Hg}$, we assumed she got pre-eclampsia. We decided to give magnesium sulphate $\left(\mathrm{MgSO}_{4}\right) 40 \%$ bolus $4 \mathrm{~g}$, continued by $1 \mathrm{~g} /$ hour and nifedipine $10 \mathrm{~mL}$ every $20 \mathrm{~min}$ four times to treat the condition. $\mathrm{MgSO}_{4}$ is the main treatment for pre-eclampsia as anticonvulsant which works in the neuromuscular junction while the nifedipine works as calcium channel blocker to lower the blood pressure. Because this patient did not give adequate information about her previous antenatal care and we need to do delivery in short period, so we gave single shot dexametason $12 \mathrm{mg}$ to prevent respiratory distress and interventricular haemorrhage for the baby. We also gave propranolol $40 \mathrm{~mL}$ which works as a beta-blocker to slower the heart rate, this drug is in Food and Drug Administration (FDA) category C for pregnant women. Furthermore, PTU was given in $600 \mathrm{~mL}$ dosage to inhibit the production of new thyroid hormone in the thyroid gland. It acts by inhibiting the enzyme thyroid peroxidase, which usually functions to convert iodide to iodine molecule and incorporate the iodine molecule into amino acid tyrosine. This drug is in old 
FDA category D for pregnancy but depend on the trimester of pregnancy as the result may vary. Other drug which can be used for hyperthyroid is methimazole. For the first trimester, PTU is the drug of choice because it has less effect on fetal birth defect. Since, PTU has more rapid onset of action and the additional benefit of inhibition of peripheral deiodinase enzyme-mediated conversion of T4 into T3, this drug is preferred in thyroid storm case. Lugol's solution or as saturated solution of potassium iodide decreases its transport into the thyroid, inhibits iodide organification (the Wolff-Chaikoff effect), and rapidly blocks the release of T4 and T3 from the gland. Potassium iodide is in FDA category $\mathrm{D}$ for pregnancy.

According to American Thyroid Association guidelines, ${ }^{5}$ treatments for thyroid storm are; (1) decreasing thyroid hormone secretion and synthesis, (2) blocking thyroid hormone effects in the tissue level, (3) reversal of systemic decompensation, (4) treating precipitating event/coexisting illness and (5) definitive therapy. Therapy includes PTU 500-1000 mL loading dose followed with $250 \mathrm{~mL} \mathrm{q} 4 \mathrm{~h}$ (PTU is more recommended than methimazole), propranolol $60-80 \mathrm{~mL} \mathrm{q} 4 \mathrm{~h}$, iodine 5 drops (250 $\mathrm{mL}$ ) q6h and hydrocortisone $300 \mathrm{~mL}$ loading dose followed by $100 \mathrm{~mL} \mathrm{q} 8 \mathrm{~h}^{5}{ }^{5}$ Our patient was treated with PTU, propranolol and Lugol solution, along with pre-eclampsia treatment of nifedipine and $\mathrm{MgSO}_{4}$.

Thyroid storms can cause life-threatening complications, with mortality rates $8 \%-25 \%$. A case report by Kitazawa et al presented a 41-year-old G1P1 woman with respiratory failure following delivery. ${ }^{6}$ The women had uncontrolled hyperthyroidism throughout pregnancy, had an unremarkable delivery, but respiratory failure occurred $9 \mathrm{~min}$ after delivery. In our patient, her respiratory rate was 40 times/min with oxygen saturation of $95 \%$, and rales are heard in most of her lung surface, suggesting acute lung oedema with impending respiratory failure.

Both our patient and Kitazawa et al's had uncontrolled hyperthyroidism, and a thyroid storm occurred within the peripartum period. It is known that heart failure occurs in $10 \%$ of cases of thyrotoxicosis in pregnancy. This is due to a decrease in peripheral vascular resistance and increased cardiac output during pregnancy. ${ }^{7}$ It was assumed that in our case, chronic uncontrolled hyperthyroidism leads to cardiac insufficiency, and added by increased stress in the delivery process caused the failure of cardiac compensation. Fortunately, our patient was successfully managed and no further complications arise.

Hyperthyroidism reduces fertility, hence, there are very few cases of hyperthyroidism in pregnancies. Studies are rarely conducted due to their rarity, and preventive acts are seldom mentioned. ${ }^{8}$ Despite the rarity, clinicians must always be aware of uncontrolled hyperthyroid in pregnant women, since it can cause devastating effects for the fetus, such as growth restriction, premature birth, low birth weight, miscarriages and also for the mother, such as pre-eclampsia, respiratory failure and death. ${ }^{9}$ General prevention of hyperthyroidism during gestation could be done by ensuring at least $200 \mu \mathrm{g}$ of iodine intake per day. Proper antenatal care should be done every month, including in it a clinical screening for hyperthyroidism or Grave's disease. Pregnant women should always avoid radiation therapy. ${ }^{10}$

Newborn who was born from hyperthyroid mother should undergone the examination to ensure there is no sign of congenital hyperthyroidism. The clinician can measure the plasma levels of free T4, T3 and TSH. Even if these are normal, they should be repeated 3-7 days later because of the possibility of the delayed appearance of hyperthyroidism. ${ }^{11}$ Some suggestion included assessing maternal TSH receptor antibodies from the cord blood. If the results are negative, no specific neonatal follow-up is needed. But if the examination is unavailable or the result is positive, we can regard the newborn as 'at risk' newborn for the development of hyperthyroidism. ${ }^{12}$

Follow-up during the first postpartum year for the mother is highly recommended in woman with hyperthyroid during pregnancy. Recurrence in the first 3 months post partum could be due to Graves' hyperthyroidism or postpartum thyroiditis. The postpartum thyroiditis occurs in $7 \%-10 \%$ of postpartum women, although this varies depending on iodine intake and genetic factors. Thyroid function tests are indicated at three and 6 months post partum in these women and those with known autoimmune disease, previous postpartum thyroiditis or chronic viral hepatitis. The pregnancy should be avoided until the thyroid function become normal. ${ }^{13}$

Patient's perspective

The patient was discharged after 5 days of treatment.

\section{Learning points}

Thyroid storm is a rare complication of hyperthyroidism.

- Delivery is an important precipitating factor, especially in pregnancies with uncontrolled hyperthyroidism.

- Thyroid storm can cause life-threatening complications, including acute decompensated heart failure, acute lung oedema and respiratory failure.

- Immediate and aggressive treatment needs to be done in patients with thyroid storms, especially in the peripartum period.

- Our case of thyroid storm in the second stage of labour is unique, and patient outcome was satisfying, despite the appalling condition at the time of admission.

Contributors YBS: study concept or design; AKH: data analysis of interpretation and data collection; BMA: data collection; FEC: writing paper.

Funding The authors have not declared a specific grant for this research from any funding agency in the public, commercial or not-for-profit sectors.

\section{Competing interests None declared.}

\section{Patient consent for publication Obtained.}

Provenance and peer review Not commissioned; externally peer reviewed.

Open access This is an open access article distributed in accordance with the Creative Commons Attribution Non Commercial (CC BY-NC 4.0) license, which permits others to distribute, remix, adapt, build upon this work non-commercially, and license their derivative works on different terms, provided the original work is properly cited and the use is non-commercial. See: http://creativecommons.org/ licenses/by-nc/4.0\%.

\section{ORCID iD}

Achmad Kemal Harzif http://orcid.org/0000-0002-3552-1610

\section{REFERENCES}

1 Prabawa A, Surya Negara K, Negara KS. Diagnosis and comprehensive management of thyroid storm in pregnancy: a case report. Biomed Pharmacol J 2018;11:1329-34.

2 Krassas GE, Poppe K, Glinoer D. Thyroid function and human reproductive health. Endocr Rev 2010;31:702-55.

3 Warnock AL, Cooper DS, Burch HB. Life-threatening thyrotoxicosis. Endocrine and Metabolic Medical Emergencies: A Clinician's Guide 2018;20:269.

$4 \mathrm{Ma} \mathrm{Y}$, Li H, Liu J, et al. Impending thyroid storm in a pregnant woman with undiagnosed hyperthyroidism. Medicine 2018;97:e9606-4.

5 Ross DS, Burch HB, Cooper DS, et al. 2016 American thyroid association guidelines for diagnosis and management of hyperthyroidism and other causes of thyrotoxicosis. Thyroid 2016;26:1343-421.

6 Kitazawa C, Aoki S, Takahashi T, et al. Acute respiratory failure due to thyroid storm developing immediately after delivery. Clin Case Rep 2015;3:997-9. 
7 Shan D, Bai Y, Chen Q-H, et al. Hyperthyroid heart disease in pregnancy: retrospective analysis of a case series and review of the literature. World I Clin Cases 2019;7:2953-62.

8 Carroll R, Matfin G. Endocrine and metabolic emergencies: thyroid storm. Ther Adv Endocrinol Metab 2010;1:139-45.

9 Marx H, Amin P, Lazarus JH. Hyperthyroidism and pregnancy. BMJ 2008;336:663-7.

$10 \mathrm{Ma} \mathrm{Y}, \mathrm{Li} \mathrm{H}$, Liu J, et al. Impending thyroid storm in a pregnant woman with undiagnosed hyperthyroidism: a case report and literature review. Medicine 2018;97:e9606
11 Polak M, Legac I, Vuillard E, et al. Congenital hyperthyroidism: the fetus as a patient. Horm Res Paediatr 2006;65:235-42.

12 Danielle CM, Kaay vander, Jonathan D, et al. Management of Neonates Born to Mothers With Graves' Disease. American Academic of Pediatric J 2016;137:1-7.

13 Ablovic Met al. Management of Thyroid Dysfunction During Pregnancy and PostPartum : An Endocrine Society Clinical Practice Guideline. J Clin Endocrinol Metab 2017:97:2543-65

Copyright 2021 BMJ Publishing Group. All rights reserved. For permission to reuse any of this content visit

https://www.bmj.com/company/products-services/rights-and-licensing/permissions/

BMJ Case Report Fellows may re-use this article for personal use and teaching without any further permission.

Become a Fellow of BMJ Case Reports today and you can:

- Submit as many cases as you like

- Enjoy fast sympathetic peer review and rapid publication of accepted articles

- Access all the published articles

Re-use any of the published material for personal use and teaching without further permission

\section{Customer Service}

If you have any further queries about your subscription, please contact our customer services team on +44 (0) 2071111105 or via email at support@bmj.com.

Visit casereports.bmj.com for more articles like this and to become a Fellow 